\title{
Effect of sand and rubber surface on the lying behavior of lame dairy cows in hospital pens
}

\author{
A. S. Bak, M. S. Herskin, and M. B. Jensen ${ }^{1}$ \\ Department of Animal Science, Aarhus University, AU-Foulum, Blichers Allé 20, DK-8830 Tjele, Denmark
}

\begin{abstract}
Housing lame cows in designated hospital pens with a soft surface may lessen the pain the animals feel when lying and changing position. This study investigated the effect of the lying surface on the behavior of lame cows in hospital pens. Thirty-two lame dairy cows were kept in individual hospital pens, provided with either 30 -cm deep-bedded sand or 24-mm rubber mats during $24 \mathrm{~h}$ in a crossover design. On each surface, the lying behavior of each cow was recorded during $18 \mathrm{~h}$. On deep-bedded sand, cows lay down more and changed position more often than when housed on the rubber surface. Furthermore, a shorter duration of lying down and getting up movements and a shorter duration of lying intention movements were observed. These results suggest that lame dairy cows are more reluctant to change position on rubber compared with sand, and that sand is more comfortable to lie on. Thus, deep bedding such as sand may provide better lying comfort for lame cows than an unbedded rubber surface.
\end{abstract}

Key words: lameness, lying behavior, flooring, animal welfare

\section{INTRODUCTION}

In modern dairy production, lameness has marked negative consequences for productivity and animal welfare (Warnick et al., 2001; Vermunt, 2007; Bruijnis et al., 2010). For years, lameness has been a serious problem with no significant reduction in the reported prevalence (20-40\%; Clarkson et al., 1996; Barker et al., 2010; Thomsen et al., 2012). Lame dairy cows, when compared with nonlame cows, spend more time lying (Chapinal et al., 2009; Ito et al., 2010; Thomsen et al., 2012) and have reduced competitive abilities (Galindo and Broom, 2002), which may explain their reduced time feeding (González et al., 2008; Gomez and Cook, 2010). Lame dairy cows kept in loose housing,

Received June 10, 2015.

Accepted December 8, 2015.

${ }^{1}$ Corresponding author: MargitBak.Jensen@anis.au.dk when moved to a hospital pen, would no longer have to deal with competition and could have a more comfortable resting place to lessen their pain; both factors may contribute to a faster recovery from lameness (Weary et al., 2009). Hospital pens are typically group pens with a deep-bedded surface (Fogsgaard et al., 2012), but for hygiene reasons it may be desirable to use a rubber surface in pens used for cows with infectious diseases. In Denmark, recent legislation requires that dairy farmers must be able to house sick or injured animals in designated hospital pens with a dry and soft surface (Anonymous, 2010). A recent study showed that lame cows prefer to lie on sand compared with rubber mats (Jensen et al., 2015). However, studies examining the effect of quality of the lying surface in hospital pens on the behavior of lame cows are lacking.

Several studies have investigated how the lying surface influences behavior of clinically healthy cows, where a soft surface has been shown to increase lying time and reduce time spent standing (Tucker and Weary, 2004; Rushen et al., 2007; van Gastelen et al., 2011). In lame cows, however, only a limited number of studies have investigated this. Studies carried out in loose housing with freestalls showed increased lying time of lame cows when the stalls were deep-bedded with sand or sawdust as compared with geotextile mattresses or rubber crumb-filled mattresses (Cook et al., 2004; Gomez and Cook, 2010; Ito et al., 2010). When comparing lying behavior of healthy versus lame cows kept on geotextile mattresses or rubber crumb-filled mattresses, the lame animals lay down less than the healthy controls (Cook et al., 2004; Gomez and Cook, 2010). In addition, Hernandez-Mendo et al. (2007) reported that the gait scores of lame cows kept in freestalls with sand bedding was reduced after 4 wk on pasture, whereas no change in gait score was found in the control cows. Consequently, the lying surface of lame cows can affect their behavior as well as recovery.

Increases in measures such as duration of lying down or getting up movements, frequency of lying down interruptions, as well as frequency and duration of lying down intention movements all indicate that the cow is having problems changing positions (Lidfors, 1989; 
Müller et al., 1989; Krohn and Munksgaard, 1993). Lying time is used to evaluate the comfort of lying surfaces for cows, and when surfaces are evaluated for cow comfort and ease of changing positions, a better insight into cow welfare is gained (Krohn and Munksgaard, 1993; Tucker and Weary, 2004). The aim of the present study was to compare effects of 2 lying surfaces (deepbedded sand versus rubber mats) on lying behavior of lame cows when housed in individual hospital pens. We hypothesized that when compared with a surface of rubber mats, a lying surface of deep-bedded sand would lead to longer lying times and increased frequency and duration of lying bouts. That cows would show increased ease of lying down and getting up movements, as indicated by shorter durations of these behavioral sequences as well as shorter durations of lying intention movements and fewer interruptions during lying down sequences.

\section{MATERIALS AND METHODS}

\section{Animals, Housing, and Management}

The experiment was carried out from September to December 2013 in the resident barn at AU-Foulum, Aarhus University, Denmark. Prior to the experiment, the cows were loose housed in a freestall barn. Freestalls were fitted with 35-mm-thick rubber mattresses (Fremtiden Staldinventar A/S, Langå, Denmark), and the alleys had a concrete slatted floor. The cows were milked twice daily in a herringbone milking parlor and fed, ad libitum, a TMR with forage-to-concentrate ratio of 60:40 (\% DM basis) for lactating cows and 80:20 for dry cows. For lactating cows, the stocking density was at least 1 freestall per cow (1.15 m wide) and at least $0.55 \mathrm{~m}$ feeding space per cow, whereas for dry cows, it was 1 freestall per cow (1.25 m wide) and $1.10 \mathrm{~m}$ of feeding space per cow. Freestalls were $1.85 \mathrm{~m}$ in length to brisket board. None of the cows had any previous experience with sand as bedding. During the experiment, the cows were fed ad libitum a TMR (same mixture as before the experiment).

\section{Inclusion and Exclusion Criteria}

The cows were selected from the 125-cow herd. Weekly gait scoring was performed by the same trained person throughout the experiment. Once a week, all lactating cows were gait scored when returning from afternoon milking, whereas dry cows were gait scored in the dry cow pen at the same time of day. Cows with a gait score of no less than 4 on a 5 -point scale, where 1 is normal gait, 4 is obviously lame, and 5 is severely lame (Thomsen et al., 2008), were superficially hoof trimmed and clinically examined in a hoof-trimming chute the next morning by the same 2 people throughout the experiment. Cows were included in the experiment if they (1) were diagnosed with a sole ulcer or white line disease (Blowey and Weaver, 2011) on one or more hooves; (2) were not diagnosed with any other clinical disease (and not treated with analgesics or any other medication); and (3) were more than \pm 14 $\mathrm{d}$ from calving. Cows diagnosed with sole hemorrhages were not included in the experiment unless they were also diagnosed with white line disease or sole ulcer. A maximum of 4 lame cows per week were included. However, if fewer than 4 lame cows per week were available, healthy and nonlame cows (gait score 1) were selected and included in the experiment to ensure a constant social environment in the barn.

Forty-two obviously or severely lame cows (gait score $\geq 4$; Thomsen et al., 2008), 39 lactating and 3 dry, were included in the experiment. The lactating cows were included in another study investigating lame cows' preferences for surface and social contact (Jensen et al., 2015). In the present experiment, 10 of the 42 cows had to be excluded. This was either due to technical issues $(n=4)$ or due to an escape from the pen $(n=1)$. Finally, 5 cows fell from a gait score 4 at introduction to a score of 1 or 2 at the end of the experiment and were excluded to ensure that all experimental cows had been lame throughout the experimental period. Thus, data from 32 lame cows were included in the present data set. Of these, 8 were first-parity, 15 second-parity, and 9 third- or later-parity cows. Thirteen of the cows were in early lactation (0-120 d in milk (DIM)), 16 in late lactation (120-414 DIM), and 3 were dry. The average weight of the cows when moved to the experimental hospital pen was $634 \mathrm{~kg}$ (range 505-866) and the average rectal temperature on the first and second day in the experimental hospital pen was $38.3^{\circ} \mathrm{C}$ (range $37.7-39)$. None of the cows had fever $\left(>39.5^{\circ} \mathrm{C}\right)$ during the experiment.

\section{Experimental Design and Procedures}

The cows were moved to 1 of 4 individual experimental hospital pens (Figure 1), in the morning of diagnosis and kept there for $6 \mathrm{~d}$. The selected cows were listed in a random order by the person gait scoring and examined in this order. The cows that met the inclusion criteria entered pens numbers 1 to 4 in the order of clinical examination. The pens were $6 \mathrm{~m} \times 9 \mathrm{~m}$ and contained a feed trough and 4 water cups, placed centrally in the pen. Each experimental cow had visual contact with the 3 other experimental cows of that week, unless cows were lying behind a solid separation (Figure 1). Each experimental cow could also obtain physical contact 
with 2 neighboring companion animals as well as the neighboring experimental cow. Each experimental hospital pen had 2 equally sized and equipped sections. One section was completely covered with a 30 -cm-deep bed of sand (mean grain size $0.322 \mathrm{~mm}$; Kosand, Dansand, Brædstrup, Denmark). The other section was covered by a rubber surface consisting of a 19-mm mat with 5-mm studs (Kura Flex, Kraiburg, Tittmoning, Germany) on which a small amount of sawdust was added daily to reduce the risk of slipping. The sand was held in place by a frame made of wooden boards. The rubber mat was fitted on plywood on top of a hard core within another wooden frame. Artificial light was turned on from 0600 to $2200 \mathrm{~h}$, and from 2200 to $0600 \mathrm{~h}$ a dim light enabled data collection from video recordings.

The experiment was carried out as a crossover design with 2 treatments, a surface of deep-bedded sand versus rubber mats. Each week, on the day of diagnosis, one cow was introduced to each of the 4 experimental hospital pens at $1030 \mathrm{~h}$. The 2 sections were divided by the feed trough and a rail on each side of the trough restricting the cows to one-half of the pen. Each week, 2 cows were restricted to sand for the first $24 \mathrm{~h}$ and then to rubber for the subsequent $24 \mathrm{~h}$, and the reverse was done for the other 2 cows. Due to the position of the gates to the pens, cows in pen I and II were restricted to rubber on d 1, and cows in pen III and IV were restricted to sand on d 1 . On d 2 at $1030 \mathrm{~h}$, the cows were moved to the other surface where they remained until the next day at $1030 \mathrm{~h}$. All cows spent $24 \mathrm{~h}$ on each surface. The cows were fed, lactating cows were milked (in the experimental pens), and pens were cleaned twice a day; between 0600 and $0700 \mathrm{~h}$ and between 1600 and 1700 h. During morning milking, rectal temperature of the cows was measured. On d 3, cows were given access to both surfaces as part of another study (Jensen et al., 2015). The cows were kept in the pens for $7 \mathrm{~d}$ after the initial lameness scoring, taken out of the hospital pens, and lameness scored again. The weekly experimental procedures are summarized in Figure 2.

\section{Behavioral Recordings}

One camera (TVCCD-624, Monacor, Bremen, Germany) above each pen allowed a side view of the whole pen and was used to record video (MSH Video, M. Shafro and Co., Riga, Latvia) for the entire stay of the

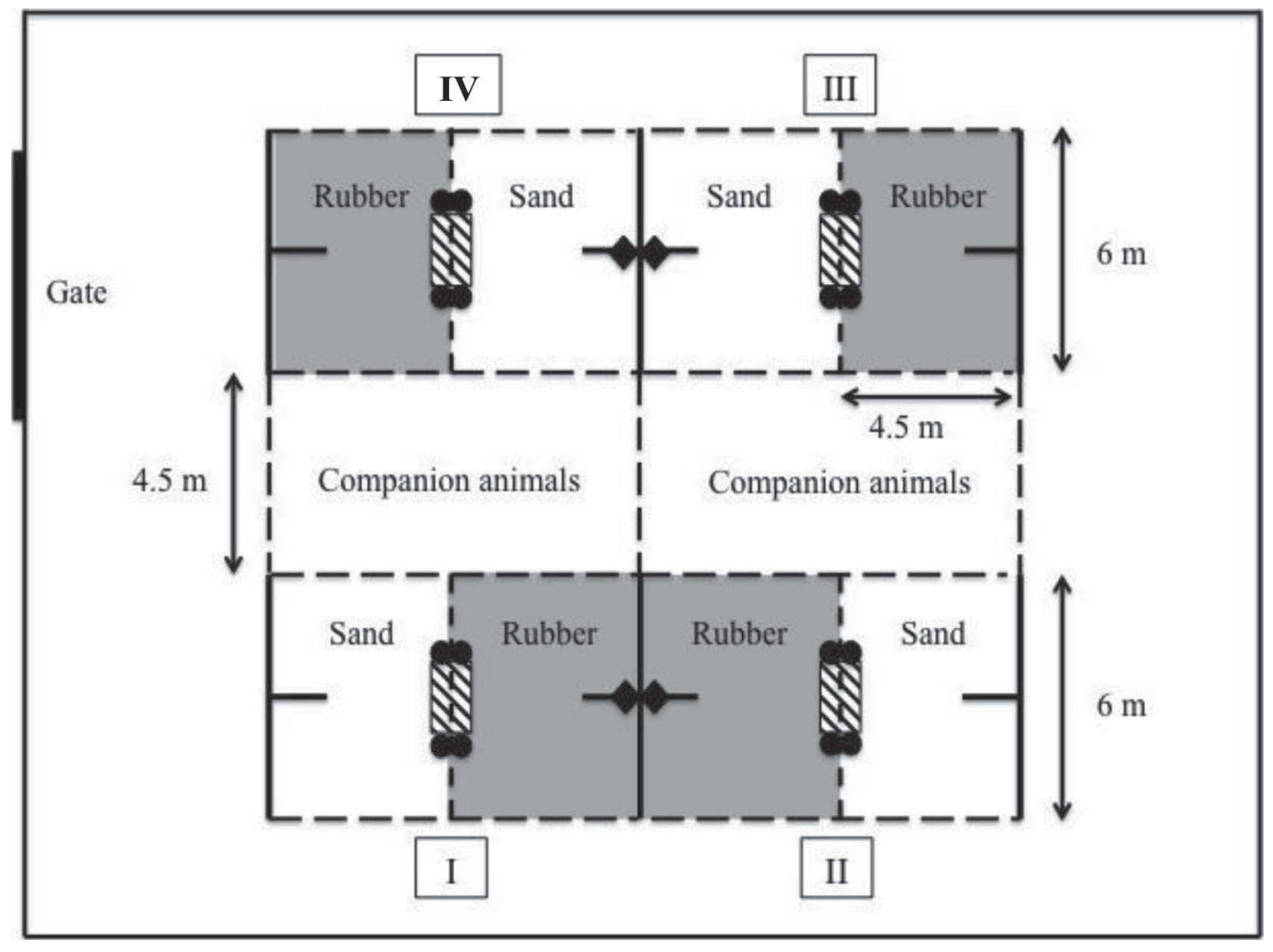

Figure 1. Floor plan of the experimental room of the barn with the 4 hospital pens used for the lame cows. Each pen was divided into 2 identical parts, with type of lying surface as the only difference. One part was bedded with $30 \mathrm{~cm}$ of sand, and the other part had 24 -mm rubber mats on the floor. Feeding trough, diagonal stripes; camera, black diamond; water cup, black circle; solid separation, solid line; bars, dashed line (modified from Jensen et al., 2015). 


\begin{tabular}{|c|c|c|c|c|}
\hline Monday & $\begin{array}{l}\text { Tuesday } \\
\text { Day } 1\end{array}$ & $\begin{array}{l}\text { Wednesday } \\
\text { Day } 2\end{array}$ & Thursday & Monday \\
\hline $\begin{array}{l}\text { 1. gait- } \\
\text { scoring }\end{array}$ & $\begin{array}{l}\text { Hoof trimming, } \\
\text { cows are moved } \\
\text { to the test pens, } \\
\text { restricted to one } \\
\text { surface }\end{array}$ & $\begin{array}{l}\text { Restricted } \\
\text { d to the } \\
\text { other } \\
\text { surface }\end{array}$ & $\begin{array}{l}\text { Allowed } \\
\text { access to } \\
\text { both } \\
\text { surfaces }\end{array}$ & $\begin{array}{l}\text { 2. gait- } \\
\text { scoring }\end{array}$ \\
\hline
\end{tabular}

Figure 2. Overview of the weekly experimental procedures. In each week, 4 cows were introduced to the experimental hospital pens after gait scoring and diagnosis. After $1 \mathrm{wk}$, the cows were gait scored again and returned to the home environment.

cows in the experimental hospital pens. Postures and behavior of the cows were scored for the 32 lame cows on both surfaces by one observer using focal animal and continuous sampling (Martin and Bateson, 2007). Video scoring was started approximately $1.5 \mathrm{~h}$ after introduction to the pens, from $1200 \mathrm{~h}$ for $18 \mathrm{~h}$ until 0600 $\mathrm{h}$ the next day. Calculated as a Pearson correlation (Microsoft Excel, Microsoft Corp., Redmond, WA) for a sample of 4 cows for $18 \mathrm{~h}$ on both lying surfaces, the intra-observer reliability was high: $99.9 \%$ agreement for total lying time $(P<0.001), 98.8 \%$ agreement for the combination of sniffing and head swinging movements $(P<0.05)$, and $88.2 \%$ agreement for getting up movements $(P<0.05$; Table 1 describes the postures and variables recorded).

\section{Statistical Analysis}

All variables were calculated for each cow on each surface. For the $18 \mathrm{~h}$, the total duration of lying, the frequency of changing position from standing to lying, as well as the average duration of a lying bout were calculated. Lying intentions were expressed by head swinging movements and the combination of sniffing and head swinging movements (termed sniffing and head swinging). For both of these, the total duration and the average duration per lying bout were calculated. Also, the number of lying bouts preceded by head swinging movements was calculated. Finally, the latency from the first head swing movement until the cow was lying down was calculated assigning a latency of zero to lying

Table 1. Ethogram of cow postures and behavior recorded using focal animal and continuous sampling during the $2 \times 18 \mathrm{~h}$ experimental periods in the hospital pens

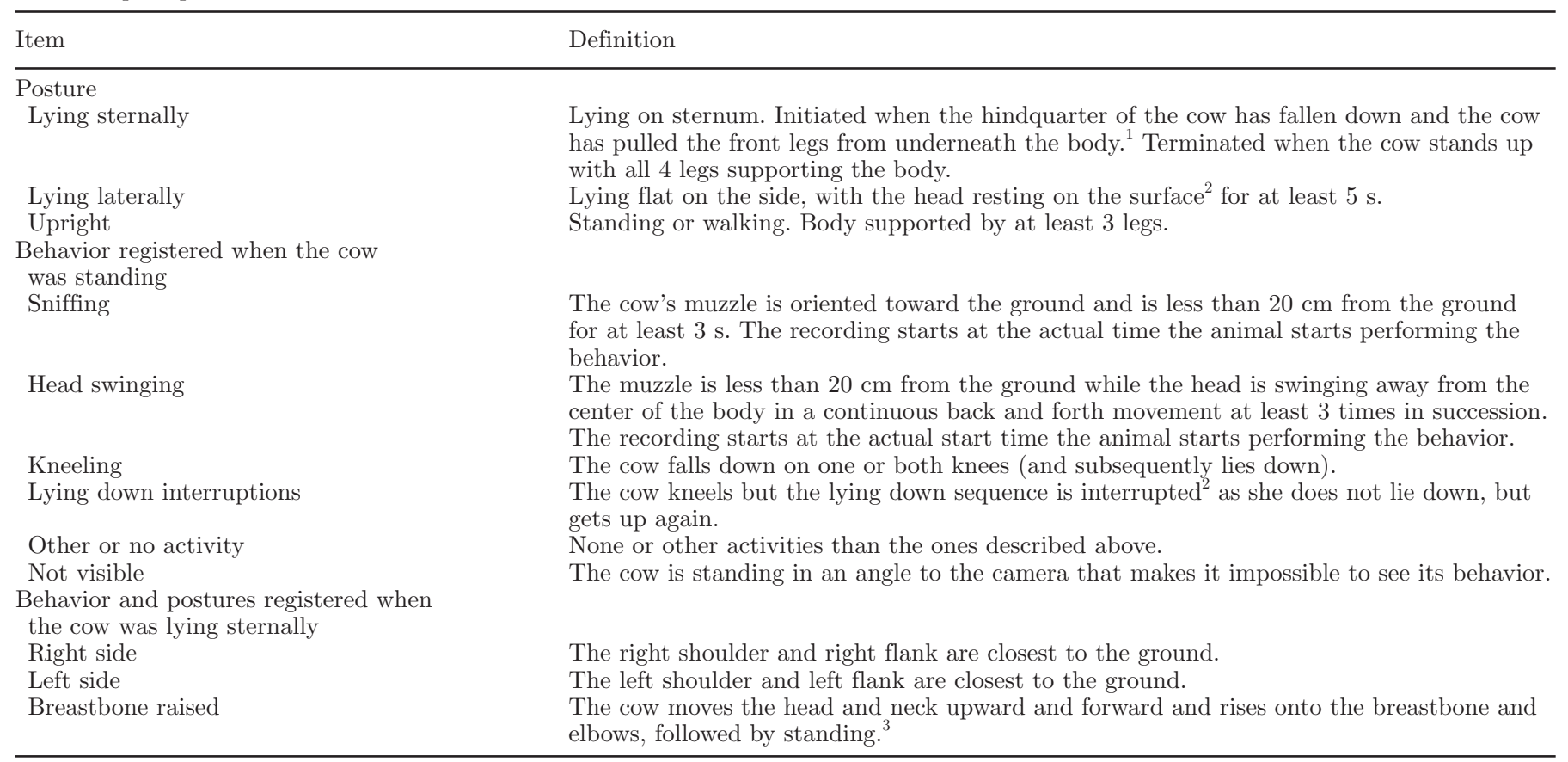

Modified from ${ }^{1}$ Plesch et al. (2010), ${ }^{2}$ Krohn and Munksgaard (1993), and ${ }^{3}$ Niss et al. (2009). 
bouts not proceeded by head swinging movements (as this situation was assumed to reflect lack of difficulty lying down). Furthermore, the average duration of the lying down movements (from kneeling until lying) and the getting up movements (from the raising of the breastbone until standing) were calculated. Finally, it was noted whether the cow interrupted the lying down movement and whether the cows lay laterally or not (Table 1) on each surface. These variables were treated as nominal data.

Variables that could not be assumed to be normally distributed were transformed by the natural log (average duration of lying down and getting up movements, latency to lie down, total and average duration of sniffing and head swinging movements) or the square root (total and average duration of head swinging movements).

All statistical analyses were performed using SAS software (version 9.4, SAS Institute Inc., Cary, NC). The variables total duration of lying, frequency and average duration of lying bouts, average duration of lying down and getting up movements, laterality, latency to lie down, total duration and average duration per bout of head swinging movements, as well as sniffing and head swinging were analyzed by a mixed model (PROC MIXED). To account for the paired observations on each cow, cow identity was included as a random effect. The model included lying surface (sand or rubber), parity (first, second, or later), and DIM [early (0-120 d), late (120-414 d) or dry] as fixed effects. Two-way interactions between lying surface and lactation number and DIM, respectively, were included. The full model was used throughout because model reduction did not improve the model fit as monitored by Akaike's information criterion. Assumptions of normality were checked by visual inspection of residual plots. The variables lying laterally and lying down interruptions were analyzed using McNemar's test (PROC FREQ).
Results from the mixed model are presented as least squares means with standard errors and $P$-values. When back-transformed means are presented, the $95 \%$ confidence interval, also back-transformed, is reported. Statistical significant differences are reported when $P$ $<0.05$, and tendencies when $0.05<P<0.10$. Effects of DIM and parity are reported when significant.

\section{RESULTS}

\section{Duration and Frequency of Lying}

When the cows were kept on deep-bedded sand, the total lying time, the number of cows observed to lie in the lateral position, and the frequency of lying bouts were higher than when kept on the rubber mats (Table 2 ). On sand, the lying time ranged from 28 min to 16 $\mathrm{h}$, and while on rubber, it ranged from $6 \mathrm{~min}$ to $14 \mathrm{~h}$. The mean duration of lying bouts and the percentage of time lying on the left side did not differ between surfaces (Table 2). However, cows in early lactation had a shorter total lying time $(8.25 \mathrm{~h}$ per $18 \mathrm{~h})$ than cows in late lactation (10.6 h per $18 \mathrm{~h})$ and dry cows (12.4 h; $\left.\mathrm{F}_{2,27}=3.7 ; P<0.05\right)$.

\section{Lying Down Movements}

The number of cows performing interruptions of lying down did not differ between the 2 surfaces, but while kept on sand, the cows lay down and got up faster than while on the rubber mats (Table 3 ).

\section{Lying Intentions}

Lying intentions included head swinging movements and the combination of sniffing and head swinging movements. Five cows were never observed head swinging on the sand, and 3 cows were never observed doing

Table 2. Least squares means of lying time and frequency of lying for the 32 lame cows kept in individual hospital pens and restricted to deep-bedded sand for $24 \mathrm{~h}$ and rubber mats for $24 \mathrm{~h}$ in a balanced order ${ }^{1}$

\begin{tabular}{lccccc}
\hline Behavioral variable & Sand & Rubber & SEM & $\mathrm{F}_{1,27}$ & $P$-value \\
\hline $\begin{array}{l}\text { Total lying time } \\
\text { Duration }\end{array}$ (h/18 h) & 12.5 & 8.3 & 0.77 & 23.22 & $<0.001$ \\
$\begin{array}{l}\text { Lying laterally } \\
\quad \text { Number of cows }\end{array}$ & 14 & 4 & - & - & $<0.01$ \\
$\begin{array}{l}\text { Lying bout } \\
\quad \text { Duration }\end{array}$ (min/bout) & 75 & 72 & 6.43 & 0.13 & $=0.718$ \\
$\quad \begin{array}{l}\text { Frequency } \\
\text { Laterality }\end{array}$ & 11 & 7 & 0.99 & 10.58 & $<0.01$ \\
Left side $^{2}(\%)$ & 52.7 & 55.2 & 4.73 & 0.17 & $=0.685$ \\
\hline
\end{tabular}

${ }^{1}$ The behavior was recorded for $18 \mathrm{~h}$ from 1200 to $0600 \mathrm{~h}$ the following morning.

${ }^{2}$ Least squares means from a mixed model accounting for cow as a random effect and lactation number, and DIM as fixed effects.

${ }^{3}$ Analyzed using McNemar's test $\left(\chi^{2}=8.33, \mathrm{df}=1\right)$. 


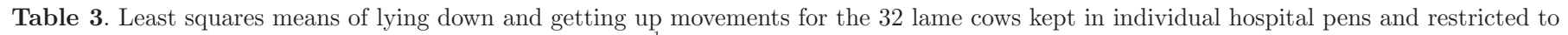
sand for $24 \mathrm{~h}$ and rubber mats for $24 \mathrm{~h}$ in a balanced order ${ }^{1}$

\begin{tabular}{|c|c|c|c|c|c|c|}
\hline Behavioral variable & Sand & CI sand & Rubber & CI rubber & $\mathrm{F}_{1,27}$ & $P$-value \\
\hline \multicolumn{7}{|l|}{ Interruptions } \\
\hline Number of cows ${ }^{2}$ & 3 & - & 5 & - & - & 0.688 \\
\hline \multicolumn{7}{|l|}{ Lying down movement } \\
\hline Duration $^{3,4}(\mathrm{~s})$ & 4.5 & 3.9 to 5.1 & 5.9 & 5.1 to 6.8 & 12.51 & $<0.01$ \\
\hline \multicolumn{7}{|l|}{ Getting up movement } \\
\hline Duration $^{3,4}(\mathrm{~s})$ & 5.0 & 4.5 to 5.6 & 5.7 & 5.6 to 6.3 & 5.80 & $<0.05$ \\
\hline
\end{tabular}

${ }^{1}$ The behavior was recorded for $18 \mathrm{~h}$ from 1200 to $0600 \mathrm{~h}$ the following morning.

${ }^{2}$ Analyzed using McNemar's test $\left(\chi^{2}=0,667\right.$, df $\left.=1\right)$.

${ }^{3}$ Least squares means from mixed model accounting for cow as a random effect and lactation number, and DIM as fixed effects.

${ }^{4}$ Back-transformed least squares means (95\% CI) where natural log-transformation was applied to the variable.

this at all. All 32 cows performed the combination of sniffing and head swinging.

The percentage of lying bouts preceded by head swinging movements did not differ between the lying surfaces (Table 4). The latency from the first head swing until the cow lay down was shorter when the cows were kept on sand compared with rubber. No difference between surfaces was found for the total duration head swinging movements, but when calculated per lying bout, the average duration of head swinging movements tended to be shorter when the cows were kept on the sand. For the combined variable (sniffing and head swinging movements), both the total duration as well as the average duration per lying bout were lower when the cows were kept on the sand (Table 4). The duration of head swinging movements was increased for third- or later-parity cows when kept on rubber compared with on sand, and on both surfaces, these cows showed an increased duration of head swinging movements compared with first parity cows (40, 126, and 82 s for first-, second-, and later-parity cows on sand and 34, 102, and $241 \mathrm{~s}$ for first-, second-, and later-parity cows on rubber; $\left.\mathrm{F}_{2,27}=3.4 ; P<0.05\right)$.

\section{DISCUSSION}

The present study is among the first to investigate the effect of lying surface on lying behavior of lame dairy cows kept in hospital pens. The higher frequency of lying bouts, the shorter latency to lie down, and the reduced performance of lying intentions suggest that severely lame dairy cows diagnosed with white line disease or sole ulcers have less difficulty lying down on deep-bedded sand compared with unbedded rubber mats. Furthermore, the greater time spent lying and in lateral lying suggest that sand is a more comfortable surface to lie on for lame cows. The results indicate that deep bedding such as sand would be a more appropriate lying surface than unbedded flooring in hospital pens for lame cows.
In the present study, the total lying duration was approximately $12 / 18 \mathrm{~h}$ on the sand and $8 / 18 \mathrm{~h}$ on the rubber mats. This higher duration of lying on sand is in agreement with results of other studies on lame dairy cows housed in freestalls with deep-sand bedding (Cook et al., 2004; Gomez and Cook, 2010; Ito et al., 2010). However, the present data were collected over 18 $\mathrm{h}$ rather than $24 \mathrm{~h}$ and are difficult to compare directly with data from these other studies. Lying times of lame cows have been shown to be longer than for healthy cows (Chapinal et al., 2009; Ito et al., 2010), whereas the present average lying time of $8 \mathrm{~h}$ on the rubber is relatively low. A low lying time for lame cows is associated with a high duration of standing still (idling) and is believed to slow down the cow's recovery from lameness (reviewed by Cook and Nordlund, 2009). Thus, the present results suggest that housing lame cows on sand is advantageous compared with harder surfaces such as unbedded rubber mats.

Some of the total lying durations observed in the present study were rather low; the minimum lying time observed on sand was 30 min, whereas the minimum on the rubber was only 6 min. Such low lying durations may be due to the very recent introduction of the cows to this novel lying surface or to the fact the cows perceive the rubber lying surface as unsuitable, or both. The experimental cows could maintain visual contact with the companion animals while lying down, and this novel social environment may also have affected lying bout duration. In future studies, increased time to habituate to the lying surface and increased observation time before data collection would be preferable. For instance, Vasseur et al. (2012) found that recording lying time over $4 \mathrm{~d}$ better reflected the average lying time over a $10 \mathrm{~d}$ period than a shorter recording time. Large variations in lying time have been reported (e.g., Leonard et al., 1996; Ito et al., 2009). In the present study design, where cows were used as their own control, large individual variation in lying time was controlled for. The shorter duration of lying early in lactation cor- 
responds to previous studies that found a reduced lying time for early lactation cows (Munksgaard et al., 2005; Vasseur et al., 2012; Deming et al., 2013).

When kept on sand, the cows had a longer total duration of lying, whereas no differences were found regarding the average duration of lying bouts as compared with when the cows were kept on rubber. The longer total duration of lying likely reflects better comfort while lying on the sand than on the rubber. This is further supported by a higher number of cows lying laterally when housed on the sand $(\mathrm{n}=14)$ compared with the rubber $(n=4)$. In preference studies lame cows have been reported to prefer deep-bedded sand to rubber mats (Jensen et al., 2015) and nonlame cows to prefer sand to mattresses (Tucker et al., 2003), suggesting that lying on sand is more comfortable for both lame and nonlame animals.

In addition to improving lying comfort, sand is believed to make the getting up and lying down movements easier for lame cows when compared with rubber mat (Cook and Nordlund, 2009). The higher frequency of lying bouts, the shorter latency to lie down, and the fewer lying intention movements observed on sand support this suggestion. Cook and Nordlund (2009) argued that sand facilitates the lying down and getting up movements, especially in lame animals, due to the cushion and traction it provides. In the present study, we quantified the duration of lying down and getting up sequences for cows and found that the cows took longer to get up and to lie down when kept on rubber mats as compared with sand. No difference in the occurrence of lying down interruptions was found between the 2 materials. However, the increased durations of lying down and getting up movements on the rubber suggests that the cows had more difficulty changing position on the rubber than on the sand; this is also supported by the lower frequency of lying bouts observed when the cows were kept on rubber. The duration of the getting up and the lying down sequences observed in the present study was relatively short compared with other studies using similar ethograms (Krohn and Munksgaard, 1993). Discrepancies between studies may be due to these types of behavior not having a clear start and end points as do other behaviors, or that the description or measures may have lacked precision. The fact that these variables had the lowest reliability among the variables tested further illustrates the challenge of consistently recording such sequences. Hence, we recommend careful definitions and descriptions of these types of behavior. In addition, we recommend only interpreting measures of the lying down and getting up movements together with measures that reflect the difficulties cows have when changing positions. 
Head swinging movements (Krohn and Munksgaard, 1993; Tucker and Weary, 2004; Niss et al., 2009) can measure the difficulty the cow has when changing positions, but only $40 \%$ of the lying down sequences observed on the sand and $50 \%$ of sequences performed on the rubber mats were preceded by this behavior. Latency from the initial head swinging movement until the animal is lying down has been used as an indirect measure of thwarted lying motivation (Müller et al., 1989; Krohn and Munksgaard, 1993; Jensen, 1999). In the present analyses, lying bouts where a cow did not perform any head swinging movements before lying down were given a latency of zero seconds, based on the assumption that this situation reflected lying down motivation not being thwarted. The present finding of 5 cows only performing the head swinging movements when kept on the rubber and not on the sand, illustrates that this behavior belonged to the behavioral repertoire of these individuals and supports the above assumption.

In addition to the head swinging movements, the present study included another measure of lying motivation, the combination of head swinging and sniffing, which is likely less specific for lying motivation than the head swinging movements alone. However, the combination was performed by all the experimental cows and recorded before all lying down events. To limit recordings of sniffing stimulated by novelty, the video analysis was initiated approximately $1.5 \mathrm{~h}$ after introduction of the cows to the surface. The fact that we found more head swinging and sniffing behavior when the cows were kept on the rubber mats compared with the sand (sand was novel to the cows, whereas rubber was not) indicates that the present findings were not expressions of exploration stimulated by novelty, but rather investigation of the surface while searching for a suitable lying place. Thus, even though a proportion of the sniffing movements may have been motivated by curiosity or represented appetitive behavior related to other motivational systems, we suggest that the increased exploratory behavior reflected the search for an appropriate lying area and hence reflected increased lying motivation.

The latency to lie down from the start of head swinging was longer when the cows were kept on rubber mats, suggesting that the cows were motivated to lie down but reluctant to do so, likely due to difficulty of performing the lying down sequence or to pain. This is supported by the lower frequency of lying bouts and the increased duration of the lying down movement on the rubber mats as compared with the sand. No difference between the lying surfaces was seen regarding the total duration of head swinging movements per 18 $\mathrm{h}$, which may be explained by the higher frequency of lying bouts on the sand. However, the cows tended to perform more head swinging movements per lying bout on the rubber mats than on sand. Furthermore, on the rubber mats, third or later parity cows were performing more head swinging movements compared with when on the sand, and these cows showed an increased occurrence of head swinging movement compared with first parity cows on both surfaces, suggesting that the lying motivation of especially older lame cows was thwarted on the rubber surface.

\section{CONCLUSIONS}

Lying behavior of lame cows kept in individual hospital pens was affected by the type of lying surface. When housed on deep-bedded sand, lame cows were less reluctant to lie down than on rubber. Furthermore, when kept on sand, lame dairy cows lay for longer and more cows lay laterally than on rubber. These results suggest that lame dairy cows have fewer difficulties lying down on deep-bedded sand than on an unbedded rubber surface, and that deep sand is more comfortable to lie on. Thus, provision of a deep-bedded lying surface, such as sand, in hospital pens may be superior to harder surfaces in terms of allowing the animals to meet their need to lie down. These findings are relevant for the future design of hospital pens for lame cows and may also be used to understand the behavior of lame cows kept in other types of housing or the effect of lying surfaces on cow comfort in general.

\section{ACKNOWLEDGMENTS}

The study was financed by the Danish Animal Welfare Centre (Glostrup, Denmark). We thank the staff at the research facility at AU-Foulum (Tjele, Denmark). Special thanks to Lars Bilde Gildbjerg (Aarhus University) for helping with data editing and thanks to Peter T. Thomsen (Aarhus University), Björn Forkman and Hans Houe (both at The University of Copenhagen) for valuable discussions on the study design.

\section{REFERENCES}

Anonymous. 2010. Law no. 520 of 26/10/2010; Ministerial order no. 470 of $15 / 05 / 2014$. https://www.retsinformation.dk/pdfPrint. aspx?id=162875.

Barker, Z. E., K. A. Leach, H. R. Whay, N. J. Bell, and D. C. J. Main. 2010. Assessment of lameness prevalence and associated risk factors in dairy herds in England and Wales. J. Dairy Sci. 93:932-941.

Blowey, R. W., and A. D. Weaver. 2011. Color Atlas of Diseases and Disorders of Cattle. Third ed. Elsevier, Edinburgh, UK.

Bruijnis, M. R. N., H. Hogeveen, and E. N. Stassen. 2010. Assessing economic consequences of foot disorders in dairy cattle using a dynamic stochastic simulation model. J. Dairy Sci. 93:2419-2432.

Chapinal, N., A. M. de Passillé, D. M. Weary, M. A. G. von Keyserlingk, and J. Rushen. 2009. Using gait score, walking speed, and 
lying behavior to detect hoof lesions in dairy cows. J. Dairy Sci. 92:4365-4374.

Clarkson, M. J., D. Y. Downham, W. B. Faull, J. W. Hughes, F. J. Manson, J. B. Merritt, R. D. Murray, W. B. Russell, J. E. Sutherst, and W. R. Ward. 1996. Incidence and prevalence of lameness in dairy cattle. Vet. Rec. 138:563-567.

Cook, N. B., T. B. Bennett, and K. V. Nordlund. 2004. Effect of freestall surface on daily activity patterns in dairy cows with relevance to lameness prevalence. J. Dairy Sci. 87:2912-2922.

Cook, N. B., and K. V. Nordlund. 2009. The influence of the environment on dairy cow behavior, claw health and herd lameness dynamics. Vet. J. 179:360-369.

Deming, J. A., R. Bergeron, K. E. Leslie, and T. J. DeVries. 2013. Associations of housing, management, milking activity, and standing and lying behavior of dairy cows milked in automatic systems. J. Dairy Sci. 96:344-351.

Fogsgaard, K. K., M. S. Herskin, P. J. Gorden, and A. M. O'Connor. 2012. Survey of management and design of hospital pens at Iowa dairy farms. Page 40 in Proc. The First Dairy Cattle Welfare Symposium, Guelph, Ontario, Canada.

Galindo, F., and D. M. Broom. 2002. The effects of lameness on social and individual behavior of dairy cows. J. Appl. Anim. Welf. Sci. 5:193-201.

Gomez, A., and N. B. Cook. 2010. Time budgets of lactating dairy cattle in commercial freestall herds. J. Dairy Sci. 93:5772-5781.

González, L. A., B. J. Tolkamp, M. P. Coffey, A. Ferret, and I. Kyriazakis. 2008. Changes in feeding behavior as possible indicators for the automatic monitoring of health disorders in dairy cows. J. Dairy Sci. 91:1017-1028.

Hernandez-Mendo, O., M. A. G. von Keyserlingk, D. M. Veira, and D. M. Weary. 2007. Effects of pasture on lameness in dairy cows. J. Dairy Sci. 90:1209-1214.

Ito, K., M. A. G. von Keyserlingk, S. J. LeBlanc, and D. M. Weary. 2010. Lying behavior as an indicator of lameness in dairy cows. J. Dairy Sci. 93:3553-3560.

Ito, K., D. M. Weary, and M. A. G. von Keyserlingk. 2009. Lying behavior: Assessing within- and between-herd variation in free-stallhoused dairy cows. J. Dairy Sci. 92:4412-4420.

Jensen, M. B. 1999. Adaptation to tethering in yearling dairy heifers assessed by the use of lying down behaviour. Appl. Anim. Behav. Sci. 62:115-123.

Jensen, M. B., M. S. Herskin, P. T. Thomsen, B. Forkman, and H. Houe. 2015. Preferences of lame cows for type of surface and level of social contact in hospital pens. J. Dairy Sci. 98:4552-4559.

Krohn, C. C., and L. Munksgaard. 1993. Behaviour of dairy cows kept in extensive (loose housing/pasture) or intensive (tie stall) environments II. Lying and lying-down behaviour. Appl. Anim. Behav. Sci. 37:1-16.

Leonard, F. C., J. M. O'Connell, and K. J. O'Farrell. 1996. Effect of overcrowding on claw health in first-calved Friesian heifers. Br. Vet. J. 152:459-472.

Lidfors, L. 1989. The use of getting up and lying down movements in the evaluation of cattle environments. Vet. Res. Commun. 13:307324
Martin, P., and P. Bateson. 2007. Measuring Behaviour: An Introductory Guide. Third ed. Cambridge University Press, Cambridge, $\mathrm{UK}$

Müller, C., J. Ladewig, H. H. Thielscher, and D. Smidt. 1989. Behavior and heart rate of heifers housed in tether stanchions without straw. Physiol. Behav. 46:751-754.

Munksgaard, L., M. B. Jensen, L. J. Pedersen, S. W. Hansen, and L. Matthews. 2005. Quantifying behavioural priorities- effects of time constraints on behaviour of dairy cows, Bos taurus. Appl. Anim. Behav. Sci. 92:3-14.

Niss, D. B. M. S. Herskin, A. M. Danscher, and M. B. Thoefner. 2009. Short communication: Rising and lying behavior of heifers before and after alimentary oligofructose overload. J. Dairy Sci. 92:617-620.

Plesch, G., N. Broerkens, S. Laister, C. Winckler, and U. Knierim. 2010. Reliability and feasibility of selected measures concerning resting behaviour for the on-farm welfare assessment in dairy cows. Appl. Anim. Behav. Sci. 126:19-26.

Rushen, J., D. Haley, and A. M. de Passille. 2007. Effect of softer flooring in tie stalls on resting behavior and leg injuries of lactating cows. J. Dairy Sci. 90:3647-3651.

Thomsen. P. T., L. Munksgaard, and J. T. Sørensen. 2012. Locomotion scores and lying behaviour are indicators of hoof lesions in dairy cows. Vet. J. 193:644-647.

Thomsen, P. T., L. Munksgaard, and F. A. Tøgersen. 2008. Evaluation of a lameness scoring system for dairy cows. J. Dairy Sci. 91:119-126.

Tucker, C. B., and D. M. Weary. 2004. Bedding on geotextile mattresses: How much is needed to improve cow comfort? J. Dairy Sci. 87:2889-2895.

Tucker, C. B., D. M. Weary, and D. Fraser. 2003. Effects of three types of free-stall surfaces on preferences and stall usage by dairy cows. J. Dairy Sci. 86:521-529.

van Gastelen, S., B. Westerlaan, D. J. Houwers, and F. J. C. M. van Eerdenburg. 2011. A study on cow comfort and risk for lameness and mastitis in relation to different types of bedding materials. J. Dairy Sci. 94:4878-4888.

Vasseur, E., J. Rushen, D. B. Haley, and A. M. de Passillé. 2012. Sampling cows to assess lying time for on-farm animal welfare assessment. J. Dairy Sci. 95:4968-4977.

Vermunt, J. J. 2007. One step closer to unravelling the pathophysiology of claw horn disruption: For the sake of the cows' welfare. Vet. J. $174: 219-220$.

Warnick, L. D., D. Janssen, C. L. Guard, and Y. T. Gröhn. 2001. The effect of lameness on milk production in dairy cows. J. Dairy Sci. 84:1988-1997.

Weary, D. M., J. M. Huzzey, and M. A. G. von Keyserlingk. 2009. Board-invited review: Using behavior to predict and identify ill health in animals. J. Anim. Sci. 87:770-777. 